\title{
Philosophy of Information: Revolution in Philosophy. Towards an Informational Metaphilosophy of Science
}

\author{
Kun $\mathrm{Wu}^{1}$ and Joseph Brenner ${ }^{1,2, *}$ \\ 1 International Center for the Philosophy of Information, Xi'an Jiaotong University, Xi'an 710048, China; \\ wukun@mail.xjtu.edu.cn \\ 2 International Center for Transdisciplinary Research, Paris c/o Chemin du Collège 1, \\ Les Diablerets 1865, Switzerland \\ * Correspondence: joe.brenner@bluewin.ch; Tel.: +41-24-492-2118
}

Received: 10 August 2017; Accepted: 21 September 2017; Published: 2 October 2017

\begin{abstract}
In the most general if unconventional terms, science is the study of how man is part of the universe. Philosophy is the study of man's ideas of the universe and how man differs from the rest of the universe. It has of course been recognized that philosophy and science are not totally disjointed. Science is in any case not a monolithic entity but refers to knowledge as the results of reasoning and both invasive and non-invasive experiment. We argue that the philosophy of science, in studying the foundations, methods and implications of science and the link between philosophy and science, must now take into account the impact of the rapidly developing science and philosophy of information. We suggest that the philosophy of information is in fact a metaphilosophy, since informational processes operate in all the sciences and their philosophies. The simplest definition of (a) metaphilosophy is that of a set of statements about (a) philosophy, and any definition of a metaphilosophy thus requires one of philosophy and of the task of philosophy as well. According to Sellars, "the aim of philosophy is to understand how things in the broadest possible sense of the term hang together in the broadest possible sense of the term". In this paper, we focus on the recursive thought underlying those statements as real processes, occurring both in and between the fundamental and the meta-level. We propose a non-standard logic, Logic in Reality, as the logic of those processes. The metaphilosophy of information is thus a framework for talking about the scientific aspects of philosophy and the philosophical aspects of science. Both Logic in Reality and the metaphilosophy of information provide a basis for understanding the physical and epistemological dynamics of existence, that is, from where the properties of things come that enable both them and the concepts of them to contrast, conflict and ultimately "hang together". We conclude that the current convergence of science and philosophy under the influence of information science constitutes a revolution in philosophy, that is, in how science and philosophy are done. Many of the issues discussed in the metaphilosophy of information may thus be viewed as part of an emerging informational metaphilosophy of science.
\end{abstract}

Keywords: convergence; science; society; logic; metaphilosophy; philosophy; non-separability; information; revolution

\section{Introduction}

\subsection{Philosophy, Science and Information}

Human beings seem driven to gain knowledge (The concept (or belief) that knowledge is justified true belief and therefore that belief is primitive will not be discussed here.) about themselves and the world beyond that required for immediate survival. Science and philosophy are the two major modes of thought to satisfy this drive, and knowledge is gained in the former by some combination of 
observation, of trial and error, and ultimately of experiment. The knowledge gained in philosophy is the result of recursive introspection and speculation about man's place in the universe-at the same time an integral part of it and different by virtue specifically of the capacity for recursive thought. Thus, in the most general terms, philosophy is primarily the study of ideas of the universe and how man differs from the rest of the universe. Science is the study of how man is part of the universe. This unconventional definition of science is an attempt to recognize and incorporate the concept that thought must in some way reflect the physical processes that constitute thinkers. The philosophy of science, in studying the foundations, methods and implications of science, not only functions as a link between philosophy and science but also has the as yet not fully recognized or accepted consequence of demonstrating their non-separability. This paper will discuss (1) the current trend toward a convergence of science and philosophy under the influence of the rapidly developing science and philosophy of information and (2) whether this trend constitutes or should be considered a revolution in philosophy. We conclude that we are witnessing the emergence of an informational metaphilosophy of science.

At the start of the 20th century, the advent of quantum mechanics radically changed the foundations of science and our philosophical conceptions of the ground of existence. In the last 25 years, a comparable rapid development in the field of information has taken place whose implications are just beginning to be understood. The development has moved from the technology and science of information, including quantum information, to the emergence, most recently, of philosophies of information. Floridi in the West [1] and independently Wu in China [2] proposed philosophies of information (PI) in response to a perceived need to place the field of information and its technology on a sound intellectual basis. The objective was to bring order into the large number of different understandings of the nature and function of information. Further, in China, Wu proposed the consideration of his philosophy of information as a metaphilosophy, incorporating all the sciences of information and that the resulting convergence of the science and philosophy of information constitutes a revolution in philosophy itself [3].

\subsection{Naturalistic Realism}

As an early precursor to this research in the West, we cite the 1975 article by C. A. Hooker [4] which defined the concept of Naturalistic Realism (NR) and explored the relationship between a science, its philosophy and an applicable metaphilosophy. Hooker's approach was congenial to us in its rejection of the distinctions of standard binary logic and an acceptance of a dialectical interaction between the physical and cognitive domains. Wu's concepts of the complex structural role of information in the extant domain, in which the purely physical-energetic and cognitive-energetic components are not totally separated or separable, is an informational version of NR.

Hooker defined a Philosophy of Science as follows: “The content of a philosophy of science comprises a theory. The theory is of the same kind as those of science in every philosophically relevant respect except logical role, insofar as the subject matter of the philosophy is science (or a science) itself". A scientific aspect of Hooker's work is its essential humanism, including (1) the idea that the goal of rational thought, the rational acceptance of beliefs and means in both science and life in general, is the maximization of human potential as well as of the depth and scope of understanding and (2) the rehabilitation of intuition as part of rational function and hence of science and (3) maintaining awareness that philosophical work does not take place in a social and ideological vacuum. These ideas, in particular that intuition and knowledge are dialectically interacting cognitive processes, are central to the non-standard logic and epistemology of Stéphane Lupasco, outlined below in Section 5.5 and discussed in detail in by Brenner in [5].

Further in this spirit, the Philosophy of Information Science is to be distinguished from Information Science by its focus on issues similar to those that serve to distinguish the philosophy of physics from physics, as discussed in a recent compendium [6]. These include questions on the one hand of the interpretation of physical theories as such and how these inform philosophical 
discussions, and on the other underlying "substrate" of the theories expressed as statements about reality, probability, space-time and so on. In the case of information, the Philosophy of Information provides a framework for inclusion of the simplest as well as the most complex "philosophical" features of Information Science, especially, meaning and value. In both cases, we feel that the emphasis should be placed on the absence of absolute separation between a science and its philosophy. This should be, in our view, a key doctrine of the Philosophy of Science. Not only are they not separated but their non-separability is their most essential categorial feature, as it is in the Logic of Reality which the cognitive dynamics of the relationship follow (Section 4.4). As we will see, our approach cuts through the debate as to whether a Philosophy of Science follows the rules and logic of philosophy, science or both.

\subsection{Outline of Paper}

It is the new functional role that we attribute to information that is central to this paper, and we therefore begin in Section 2 with an outline of the recent evolution and current status of the field of information, of which the study of information is a part. Section 3 summarizes the basic concepts of the structure and role of Wu's Philosophy and Metaphilosophy of Information, based on his segmentation of the existential field and the concept of grades of information. Section 4 consists of a summary of the key aspects of Brenner's Logic in Reality-LIR [5] necessary to show the basis for its application to the science and philosophy of information. This section includes our concept of non-separability as a categorial feature that is central to our ontological approach. As a general logic of change, LIR applies to the major changes that constitute revolution. For the subsequent discussion, as we were dissatisfied with aspects of standard approaches to science for this discussion, we suggested an additional perspective in Section 5.

We then summarize, in Section 6, the concept, extensively discussed since the work of Thomas Kuhn, of revolution in science and contrast it with the limited literature on revolution in philosophy. Section 7 returns to the theory of the philosophy of information as a metaphilosophy of $\mathrm{Wu}$ and on the impact of information on philosophy. This is the background for our discussion of the paradigmatic status of what we describe as an informational turn. It is an introduction to Section 8, which looks more deeply into the impact of information on philosophy and Section 9, which presents evidence for the current interaction and convergence of the science and philosophy of information. Section 10 discusses whether or not unity and unification, including a potential Unified Science-Philosophy of Information (USPI), are appropriate goals of theory.

In Section 11, we argue that the current developments in Information Science and Philosophy leading to a USPI, that is, a convergence of science and philosophy, under the influence of information, defines a discontinuity in thought that justifies calling this informational turn a revolution in philosophy itself. We therefore suggest that any proper new philosophy of science is an informational metaphilosophy, in that (the science of) information defines both new content of the philosophy of science and new dynamics of the relations between a science and its philosophy. We conclude that all of the issues and attitudes discussed in this Special Issue may be viewed as part of an emerging informational metaphilosophy of science.

\section{Information and Information Science}

\subsection{From Communication and Information Theory to Information Science}

As analyzed by $\mathrm{Wu}$ [7], from an historical standpoint, the universal character of the concepts of information and information systems had as a consequence that the scientific study of information problems went rapidly beyond the field of communication science. After the birth of information theory, there was a rapid and general expansion of the fields of its application. Not only were formed the three major branches of information theory-technology information theory; semantic information theory and information utility theory, but also informational concepts, processes and methods were 
found and applied in almost all fields of natural and social science and thought. There has never been any single subject that has had such a wide range of adaptability and comprehensive application to human knowledge as information in the fields of organization, linguistics, neurology, physiology and psychology to mention only a few.

With development of information theory and related subjects in science including electronics, automation, computer science, and other technical and theoretical subjects, communication theory evolved into the new discipline of Information Science (IS). IS included and integrated systems and methods especially from computer science and Artificial Intelligence as well aspects of the operation of these methods in all standard sciences from physics to the cognitive and life sciences and cosmology.

The establishment and development of Information Science as a separate discipline is thus a new development in science itself. Information Science is not a single or cross-disciplinary subject, but an inter- or transdisciplinary subject system consisting of many levels and disciplines. We see the practice of Information Science, involving the attention paid to the complex interactions between fields, as taking on a wider causal role in the transformation of the essential forms and functions of the sciences in general. This transformation can be considered as part of a new scientific or knowledge paradigm in which information theory and science are the dominant modes of knowledge acquisition.

One of the consequences of the rapidity of these changes is that there is no language to describe adequately the profound informational transformation of the form and function of science. That language has itself to be "informational", and it is this idea that suggested the term "informational scientification" to represent the recursive coupling of the interdependent components of science and information science [2].

An earlier version of this paper included a hierarchical ordering of the fields and sub-fields of the complex system of disciplines of Information Science as follows: a General Theory of Information (1), a Philosophy of Information (2), a Unified Theory of Information (3), Information Science (4), different kinds of Informatics (5) and an Informational Knowledge Paradigm (6). In the interim, this classification has become less significant than the changes that we have identified in Information Science and the Philosophy of Information in the direction of their convergence. Questions of unity and unification in science and philosophy remain of central interest and are discussed in Section 9.

\section{Informatics}

This paper would not be complete without some additional comments on the characteristics of Informatics, considered by some of its practitioners as a full-fledged, integrated science in its own right, with its own laws and methods [8]. The evolution of Informatics roughly tracks that of Information Science and has been studied in China by Xueshan Yan, Huacan He and others. In 2008, Zong-Rong Li and his colleagues suggested a new framework for Information Science in terms of six categories-" $1+4+3$ "-in which 1 refers to Theoretical Informatics; 4 to the underlying theories and technologies, communication theory, cybernetics, computer science and robotics; and 3 to three levels of application in engineering, social science and humanities. The work of the Authors of this paper can be considered within the scope of Theoretical Informatics [9]. In Li's view, it embodies the philosophy of information, an informational worldview, the relation of matter-energy and information and so on, in other words the issues touched on in this paper.

Any debate about whether Information Science, Informatics, or a Philosophy or Metaphilosophy of Information or Informatics is more adequate as a framework for discussion will not be entered into here. As noted above, the work of Wu in China and the publications of A. D. Ursul in Russia since the 1970s are classical works in the area [10]. To the extent that the theories of Ursul, K. K. Kolin [8] and Li illuminate the nature of information there is no necessary disjunction with ours, but it would be outside the scope of this paper to make a further comparative analysis of them. In the view of Xueshan Yan, despite some prior questioning, the term Informatics remains necessary to delineate at least two applied aspects of information theory: research in information technology and research about information. The term Theoretical Informatics is close to that of "Foundations of Information Science" 
of Marijuan and of "Metaphilosophy of Information" of Wu. A complete picture of the implications of the various usages has been presented by Yan [11] in his recent book in Chinese.

\subsection{Further Definitions and Functions of Information Science}

Typical academic definitions of Information Science are (1) the foundation of various disciplines which take information as the main object of study; (2) a discipline that studies the laws and movement of information; and (3) a comprehensive interdisciplinary subject that uses information theory to describe, simulate and control the flow of information in real systems. It can be called one of the three leading-edge disciplines together with the life sciences and materials science.

However, just as information and information systems have the most general and universal character and the broadest meaning and scope, in comparison with matter and material systems, Information Science has the broadest scope of any science including as its subjects of study the analysis, collection, classification, manipulation, storage, retrieval, laws of movement and dissemination of information, divided into appropriate levels and categories. The subjects are highly interdependent and cannot be completely separated. The material (energetic) and non-material aspects of information and its laws of evolution transmission, reception are always inherently unified as discussed by $\mathrm{Wu}$ [12]. As noted above, Information Science cannot be regarded as a single simple discipline, and it cannot be explained comprehensively just by the terms of cross-, inter- or transdisciplinarity and comprehensiveness, although all of these terms can be useful.

The position and role of Information Science can also not be simply compared with the life sciences and material sciences since it is more universal than them. They must now incorporate relevant theories and methods provided by Information Science. The life sciences study the general laws and methods of the occurrence, development, movement, transformation, change and recombination of essential biological and genetic information, and the material sciences study the general mechanism and methods of the functioning, processing, compounding and construction of the essential informational structure of material objects. From this point of view, the essential informational content of research in these disciplines is contained within Information Science.

Information Science (IS) has developed concomitantly with related approaches to modern science, including systems theory and science. In fact, IS cannot be totally separated from subjects also studied in Systems Science. However, as shown in a recent paper [13], Information Science and what Wu has called Informational Thinking (IT) go beyond Systems Science and Systems Thinking (ST) with respect to many if not all major areas of current research.

A key link between the science and philosophy of information has been made by Marcin Schroeder [14] who writes, speaking of the concept of information: "Also, it is important to develop some standards of inquiry, which would make information scientific studies accessible to philosophical analysis and reflection. In turn, contributions of information science to the resolution of problems identified within philosophy will give the best measure of maturity for information science as a discipline." Let us now turn directly to the Philosophy of Information.

\section{The Philosophy and Metaphilosophy of Information of Wu}

\subsection{The Information Age}

It has become commonplace to say that we live in an Information Age and/or that we belong to an Information Society, but there is still little agreement on what information is. In our opinion, part of the difficulty in achieving a workable consensus about information is its multi-faceted nature, in which technological, scientific-theoretic and philosophical components are present. In this regard, work in the relatively new domain of the Philosophy of Information, in Russia, China and in the West as noted above, has resulted in some new epistemological and ontological concepts of information independently of its origins in communication theory and its embodiment and functioning in computational technology and Information Science. 
It has also become common to deplore the multiplication of disciplines and the consequent fragmentation of knowledge, in part facilitated by the availability of the Information and Communication Technologies (ICTs). In this paper, we offer a more optimistic view, suggesting the possibility of a partial defragmentation of knowledge by the identification and application of some general informational principles within science, philosophy and logic, which have gone unnoticed to date. The operation of these principles is particularly visible not only in establishing the nature and properties of information and information processes, but also in analyzing their impacts on science and philosophy themselves.

\subsection{The Emergence of a Philosophy of Information}

The first work on the Philosophy of Information on which this paper is based was carried out by $\mathrm{Wu}$ [2] starting in the 1980s. A. D. Ursul in (now) Russia should receive historical credit for the earliest publication in this field [9], work like that of $\mathrm{Wu}$ hidden behind the language barrier. A small part of Wu's work became available in English $[15,16]$ after the 4th International Conference on the Foundations of Information Science in Beijing in 2010. In particular, the comprehensive, recursive informational process of development was named by Wu "The Informational Scientification of Science" [15] (Wu prefers the neologism of "scientification" to the more familiar one of naturalization since, as should be obvious, the latter only applies to domains of knowledge that are normally considered outside science.). Following this Conference the authors found that this theory is supported by the extension of logic to real phenomena by Brenner-Logic in Reality; LIR [5], grounded in the dualistic quantum-mechanical properties of energy. In our joint theory, there is an informational and logical continuum from the Philosophy of Information to that of the sciences of perception, cognition and social evolution and their respective philosophies as well as to the other sciences formalized as their informational counterparts.

The Italian philosopher Luciano Floridi, now at the University of Oxford in U.K., is the pioneer of the field of the Philosophy of Information in the West as Wu is in China [1]. In the definition of Floridi, the Philosophy of Information (PI) "is the philosophical field concerned with (a) the critical investigation of the conceptual nature and basic principles of information, including its dynamics, utilization and sciences; and (b) the elaboration and application of information-theoretic and computational methodologies to philosophical problems. The dynamics of information is further defined (in part) as "the constitution and modeling of information environments, including their systemic properties, forms of interaction, internal developments, etc." We will return to his work later in connection with the metaphilosophy of $\mathrm{Wu}$.

The first consequence is that to approach correctly today the concept of science, that is, within the context of a Philosophy of Science, we must see what the effect of the incorporation of a science of information might be. The impact of the informationalization of science is thus taking place on two levels: on science (1) as an experimental, intrusive practice and (2) as a cognitive discipline in which the major object is as elusive as change itself. We submit that these notions lead, ipso facto, to a new picture of the Philosophy of Science as a complex together with the Philosophy of Information. Some consensus is developing that information is a new kind of object of scientific study, instantiating a fundamental dualism. Based on this dualism, $\mathrm{Wu}$ has presented a new interpretation of critical philosophical concepts, especially, the segmentation of the existential field, leading to a formulation of a Metaphilosophy of Information having a central role in the acquisition of knowledge [17]. Let us now look at Wu's approach in detail.

\subsection{The Segmentation of the Existential Field}

Information is somehow associated with or constitutive of existence, but it has proven notoriously difficult to define and characterize, due to its multiple duality: it has both physical and apparently non-physical components. Information is both meaningful and a carrier of meaning. Information can be viewed as well-defined data [1], processes [18], referring to what is not or not yet "there" [19] and 
in many other ways. As Wu has stated elsewhere, to approach correctly a concept considered part of standard science-information-we must reexamine the entire philosophical structure of transmitted human knowledge!

Thus, for us the most important innovation has been Wu's Basic Theory of the Philosophy of Information (BTPI) [2] that states that a new segmentation of the field of existence (the extant domain) is required to properly define information. In order to explore the essence of information, it is necessary to first examine the scope of the field of existence itself-the existential field. In this approach, all the "existence" in the whole universe (the world, nature) can be put into the categories of objective reality, objective unreality and subjective unreality as its three major divisions. The scope of objective existence is thus broader than objective reality (matter). The material category does not include the entire mental "world". There is a field of "objective unreality" between the material and mental to which traditional science and philosophy have not paid adequate attention, even when it is given a physicalist interpretation.

Wu thus defines information from a philosophical perspective as a category that indicates the presence of indirect existence, which is a self-display by material entities (with direct existence) of the status and trajectory of that existence. In Wu [20] in English, based in part on articles published only in Chinese over the last 30 years, information is shown to include three basic forms: in-itself, for-itself and regenerated information, which is constituted by the first two. Information in these three basic forms establishes the essence of information, which is further developed in a fourth form-social information.

Information is further characterized by the qualities of its three different grades, corresponding to these forms: The quality of first-grade information demonstrates direct objective existence and indirect objective existence; the quality of second-grade information demonstrates multiple levels of direct objective and indirect objective existence; the quality of third-grade information is that of the subjective relationships in human understanding that are encoded as information.

The grounding of information in the ontological structure of the world gives it a central role in the approach to knowledge, constituting a new and necessary critique of the classical separation of the academic disciplines and the bases of modern philosophy. This leads to a new worldview, a new existential picture of world in informational terms. In particular, we will see that our approach confers an ontological dimension to the categorial discussions of information theory that have been largely epistemological. We will return to this conception of information after we look at problem of a logic for information in relation to the Philosophy of Information and Information Science.

\section{Logic and the Nature of Information}

\subsection{The Problem of Logic}

In his discussion of the computational philosophy of science [21], Thagard noted that processes going beyond standard deductive logic were required in scientific discovery, but did not propose anything more radical that the adjunction of induction and abduction. In fact, few discussions of logic are to be found to date in discussions of complex phenomena such as change, intentionality, intelligence and information for the good, if unfortunate, reason that standard propositional, truth-functional logics, even in their modern modal and epistemic forms, are incapable of handling the recursive and topic non-neutral features of complex processes and, indeed, of information other than at the lowest computationally defined level. Binary truth-functional propositional logics, even in their modern modal, doxastic and deontic forms, serve as the underpinnings of a current scientific paradigm from which the validity of certain $1^{\text {st }}$-person experience and questions of human values are almost totally absent. If such issues are discussed in terms of logic at all, it is essentially metaphorically, as a more or less classically structured system of beliefs and practices. Standard logics, and the entirely equivalent disciplines of set and category theory, are not designed for the analysis of either fundamental ontological questions or complex psychological and socio-economic phenomena, such as that of art. 
The exclusion of critical domains of thought involving questions of change, consciousness and the self and ethics from logic and, therefore, from science in its original conception of knowledge of all nature, seems unsatisfactory. Change is ubiquitous in existence and experience. Theories of change, however, have focused on making it mathematically, computationally and logically tractable, within the framework of standard logic. In fact, change is contradictory: it is regular and irregular; consistent and inconsistent; continuous and discontinuous. Since the only logics available are incapable of accepting real contradictions, they have been incapable of describing change.

All approaches to such phenomena thus suffer from more or less explicit dependence on underlying logics, bivalent or multivalent, that are semantic and truth-functional, including their most recent modal, epistemic, doxastic and paracomplete (intuitionist) versions. These logics require, among other things, absolute separation of continuity and discontinuity, space-time and matter, chance and necessity, etc., and lead to the paradoxes with which we are all familiar. Even paraconsistent logics, which accept contradiction, capture only the linguistic, as opposed to the physical, aspects of processes, although some real inconsistencies in simple change (Sorites problems) are accepted. Logics of epistemic change [22] are based on linguistic abstractions from which physical processes have been largely eliminated.

\subsection{Logic in Reality (LIR)}

The new logical approach, which we will argue is applicable to complex cognitive and informational processes, is an extension and updating of original work by the Franco-Romanian thinker Stéphane Lupasco (Bucharest, 1900-Paris, 1988). This new perspective, which Brenner has designated as Logic in Reality (LIR) [5] focuses on the connections, rather than the distinctions, between phenomena and provides a new basis for the discussion of moral issues in a more principled, scientific manner. LIR is thus an entirely new kind of non-propositional logic grounded in the fundamental self-dualities and dualities in the nature of energy or its effective quantum field equivalent. These antagonistic dualities can be formalized as a structural, logical and metaphysical principle of opposition or contradiction instantiated in complex higher-level phenomena. The fundamental postulate of LIR is that for all energetic phenomena (all phenomena) alternate between degrees of actualization and of potentialization of themselves and their opposites or "contradictions" but without either going to the absolute limits of 0 or $100 \%$.

The LIR logical system has a formal part-axioms, semantics and calculus; an interpreted part consisting of a metaphysics and a categorial ontology; and a two-level framework for analysis relating levels of explanation. LIR is neither a physics nor a cosmology but a logic that enables stable patterns of inference to be made, albeit with reference to probability-like metavariables. In LIR, processes are constituted by series of series, etc., of reciprocally determined actualizations and potentializations of entities and their opposites, and emergent states, driven by the overall energy gradient of the universe. Causality, determinism and indeterminism, time and space, parts and wholes, etc. receive non-standard interpretations in this theory.

LIR captures the dynamic structure of the non-separable and inconsistent aspects of complex entities, processes and events at biological, cognitive and social levels of reality. Real entities can be described as encoding significant energy in potential form, as capacity for interaction. Both the actual and potential states of particles at lower levels-atoms, molecules, biopolymers, cells, etc.-are functional. The residual potentialities of entities at any level are the carriers of the information necessary for upward causation and emergence at the next higher level. This grounds, in basic physics, the concepts of "auto"-catalysis and "self"-organization in evolution and morphogenesis.

\subsection{Information in LIR}

Given its contradictorial approach to all complex real phenomena, LIR can be seen as a logical methodology that would encourage the retention and use of partially conflicting notions and theories of information, among others. LIR thus can provide bridging concepts or "glue" between the 
concept of semantic information at the lowest data level and broader applications. LIR places this concept, and thus Hofkirchner's "superconcept" [23] of information, in a naturalized physical, metaphysical and logical context. Information is both a means to model the world and part of the world that is modeled, and LIR describes the dialectic relation between them. An anonymous reviewer has referred-negatively-to our references to dialectics as "Leninist" logic. Hegel distinguished between dialectics and formal logic - which was for him the Aristotelian logic of his day. The law of non-contradiction holds in formal logic, but it is applicable without modification only in the limited domain of the static and changeless. In what is generally understood as dialectical logic, which Logic in Reality superficially resembles, the law of non-contradiction fails. The subsequent developments of formal logic, starting with Frege and Russell, have forced Hegel's conception of contradiction to be rejected or interpreted non-literally. Lenin is a neo-Hegelian some of whose ideas are close to LIR: "Logical concepts have an abstract form but at the same time express things in themselves". One must focus on the dynamic interaction between subject and object, identity and difference. Consequently, readers should not think that any use of the term "dialectics" implies the untenable political positions of Marxism-Leninism. Some of its philosophical insights are valid and do not need or deserve to be discarded a priori.

Floridi found the concept that semantic information is true if it points to the actual state of the world somewhat equivocal, but I believe its fits the LIR processual logic, in that logical (in the LIR sense) information, as a set of informational processes, is the actual state of the world.

To repeat, Logic in Reality does not pretend to offer or to constitute an independent theory of information that would supersede any or all existing approaches. LIR provides a new interpretation of the concept of qualitative information or information-as-process as contrasted with quantitative information. We distinguish between information-as-process (information-in-itself) and information processing. The latter is usually thought of as computation, but our approach includes non-computational operations of thought. What LIR does offer is a way of explicating aspects of the dualistic nature of information, (properties that one could say LIR is "designed" to handle) as they appear, for example, in the theory of $\mathrm{Wu}$.

We do not claim to be the first to emphasize the need for scientific disciplines to accept the qualitative properties of physical phenomena as logical elements of them. Colin McGinn recognized this in his Basic Structures of Reality [24] referring to the intuition of Bertrand Russell that percepts cannot be reduced to the structural-mathematical abstractions of physics. Physics gives only the causal skeleton of physical reality, but percepts are "thick" realities that cannot be reduced to what is ontologically "thin". The (relative) thinness of physics needs to be supplemented by the thickness supplied by percepts, but our informational-logical approach provides the basis for going beyond McGinn's "mysterian" concept. Cognition and perception are informational processes that follow the dynamic logic of interaction [25], while avoiding slippage in the direction of a pan-psychism that is as false as standard physicalism.

\subsection{Further Implications for Philosophy}

Symons [26] has given several arguments explaining why logic has had a minimal role in the mainstream Philosophy of Science, but he himself has applied epistemic logic directly to the neuroscientific study of perception and identification and showed that epistemic logic can model the natural phenomenon of knowledge seeking. LIR supports this applied approach. To use Quine's phrase, as "a compendium of the broadest traits of reality" [17] rather than a linguistic system, LIR offers a principled way of establishing a link between empirical science and logic, with empirical evidence logically able to support a unified system of knowledge, better, a Unified Science of Information, which in the view of Wu includes related fields of knowledge such as design and engineering (see his discussion of the Philosophy of Information below).

Derrida [27] questioned the structure of standard binary oppositions, and said that "différance" "invites us to undo the need for balanced equations, to see if each term in an opposition is not 
after all an accomplice of the other." LIR takes this intuition and provides a new "structure" of oppositions and reading of "being an accomplice". The "difference" in the famous statement of Bateson, that information is a difference that makes a difference, can be seen as a différance.

In LIR, the structure of reality does not depend on any transcendental notion of human experience as proposed by Heidegger and in the neo-Kantian phenomenology of Petitot. The dynamics of physical processes may be described without reduction. This logic is not that of logical positivism or of Hempel. It is part, rather, of a new ontological turn in philosophy (see below, Section 8.1 on the informational turn).

\subsection{Non-Separability}

In discussing the philosophy of a science, one begins by assuming that that the science has subject matter, goals or objectives and a methodology for attempting to reach those goals. If we also require of a philosophy that it tell us something about reality, both as described by that field and others, it should be obvious, as it was to Hooker that there is no total separation between the science and its philosophy. Even if the latter is best described by the term "reflections on", this term conveys the idea of a higher level, reflexive or recursive cognitive process. This description, we believe, applies in general to the Philosophy of Science.

The problem is that non-separability as a logical as well as scientific principle is not widely accepted as such for the common but bad reason that it conflicts with standard propositional and Boolean logics, as well as standard set and category theory. These doctrines are (still) at the basis of much reasoning about topics in both science and philosophy. However, they fail to provide access to much of reality that cannot be modeled mathematically, that is, for which no algorithm can be written. Inconsistent or paraconsistent logics only go part of the way toward reality, as they retain the linguistic, truth-functional criteria of standard logics [28]. In this section, we discuss several concepts central to our approach to which the principle of non-separability as defined ontologically in LIR is essential.

\subsubsection{Dogmatism and Scientism}

We are not so naïve as to believe that there are no countervailing trends in philosophy as LIR would predict. Wu has discussed the need to "fight" against the unconditional separation between science and philosophy. In a compendium on the "Future of Philosophy", philosophy is defined as "the transdiscipline that questions the assumptions and interrogates the values and claims to knowledge of all other disciplines recognizing their significant value in relation to each other and asking new questions and opening new paths of inquiry". Philosophy opposes science only as scientism, viewing science and its standard methods as exclusive, which "far from advancing science, has only advanced technoscience". Genuine science is the systematic effort, inseparable from philosophy (emphasis ours), to comprehend the world in all its diversity [29].

Despite the absence of references to information, we can agree with this statement, but not with the superannuated doctrine in a compendium in the same series entitled "Foundations of Mind: Cognition and Consciousness" [30]. Here we read that science is to be characterized in terms of nihilism, not in what science implies, but as the very essence of science as such, a perpetual disavowal of subjectivity due to the repressed Cartesian split at its core. This is one expression of the gap we hope that LIR and the science and philosophy of information may help to bridge.

\subsubsection{Complementarity}

Bohr's principle of complementarity as a fundamental aspect of quantum objects is one of the major advances in thought of the 20th century. Bohr asked physicists, essentially, to accept A and non-A, wave and particle characteristics of a quantum particle, and its space-time description (kinematic) and causal (dynamic) descriptions at the same time. More accurately, the explanandum was that A or non-A was observed depending on what theoretical or experimental questions were being asked. 
However, what could this mean? In the absence of a firm definition by Bohr, the complementarity principle came to be discussed as something like a simple juxtaposition.

The LIR view of complementarity is in total disagreement with that presented by the physicist and philosopher of science John A. Wheeler. Wheeler wrote [31] that complementarity ... represents in one sense the most revolutionary (emphasis ours) conception of our day; the title of the sub-section was "Complementarity: Powerful Guard against Contradictions". He also wrote, "free will and determinism are complementary concepts, not contradictory; the two can never come into use at the same time". Brenner has amply documented the need to rehabilitate contradiction in logic and philosophy.

Bohr was apparently suspicious of the ability of various modifications of classical logic, as it was understood in the mid-20th century, to assist in the definition of quantum physics, although the failure of non-commutativity and non-distributivity of quantum variables, which suggest non-Boolean algebra and logics, were well known. It was only in the 1980s, with the advent of paraconsistent logics, that a new approach to the formal explanation of the principle of complementarity became possible. However, the paraconsistent logician Béziau states that "there is no principle of complementarity, and complementarity is just a word for some philosophical ideas, for an insight that Bohr was never able to formulate in a clear way." It is correct to say that the common understanding of complementarity is too vague to be of metaphysical value. However, I also feel that Bohr, toward the end of his life, seems to have moved toward a more ontological interpretation: phenomena or information were mentioned as being complementary, rather than descriptions. "The phenomenon by which in the atomic domain objects exhibit the properties of both particles and waves that in classical, macroscopic physics are mutually exclusive categories." This is a coherent philosophy in that it accepts a concept, which is the fundamental concept of LIR, of the complementarity of opposites in both an epistemological and ontological sense.

If, as suggested by Lupasco [5], dynamic opposition is a fundamental principle of existence, a real contradictorial relation in quantum phenomena is neither physically nor logically unacceptable, and it can have both epistemological and ontological aspects. It is not physically unacceptable because wave and particle properties are not fully instantiated at the same time, until the measurement of one potentializes the other. It is not logically unacceptable for exactly the same reason. Two answers can be given to the objection that this formulation simply restates the result of experiment: (1) if the particle aspects are actualized, the wave aspects must be present as potential, and vice versa, otherwise it is difficult to explain how they could reappear; (2) it is not in the LIR view that there is any problem with the observed duality of quantum entities in the first place.

\subsubsection{The Metalogical Rejunction}

There is a further reason for including the Lupasco discussion of the relation of science and logic in this paper on the relation of science and philosophy. The original work of Lupasco can also be seen as a bridge or intermediate explanatory structure between the disciplines and the realities they discuss. Brenner feels that Lupasco effected a return of logic to its original sense of a global science of nature, which one might call a metalogical "rejunction" [32]. No diminishing of the value of standard logic in its appropriate domain of evaluation of statements about reality is intended or implied. However, Lupasco's logical theory [33] and LIR are at the same time scientific theories and, to the extent that their physical postulates or underpinnings could be disproved, they could meet Popper's criterion of falsifiability. In another sense, they are metatheories that propose analyzing the extent to which other theories adequately represent the non-separable properties of real phenomena. Thus, there is in Lupasco and LIR a possible new criterion of falsifiability as partial falsehood. However, it is clear that their more general acceptance and application require a shift from focus on the axioms and formalism of classical and neo-classical propositional or mathematical logic as the criteria of a valid logical system. One corollary of LIR is the necessary logical existence hence the scientific nature of irrational, non- or anti-scientific positions. Such positions are supported by a great deal of energy and 
obviously correspond to certain fundamental human structures and needs. They can, however, be easily assimilated into the Philosophy of Science in our informational framework and the motivations and reasons for their existence understood.

The Philosophy of Information of $\mathrm{Wu}$ [2] that now accompanies the expansion of the fields of Information Science and Technology deserves our attention because it illustrates the principle of the Lupasco logic indicated above. To summarize this section, we may say that it is the inherent inability of standard logics to handle change that disqualifies them as a basis for understanding the world. LIR attempts to take the world as it is, in all its complexities and contradictions or better countervalences as the basis for understanding it. It provides a counterexample to the view, in a standard late 20th century text by Hesse, that the logic of science is "circular" because theory and data constrain one another [34].

The characteristics of information, as they are codified in the Philosophy of Information as a Metaphilosophy, have impacts on science and philosophy that in fact indicate the reduction of the separation between them. It is this relation that we will explore as the major new contribution of $\mathrm{Wu}$ for which the LIR of Brenner provides some of the tools. Since, however, we were not satisfied with the monolithic use of the term "science", we suggest some necessary distinctions.

\section{What Is "Science"?}

\subsection{A Segmentation of Science}

As we pursued this research, we found it important to emphasize that "science" should not be viewed and referred to as an identity, but as composed of many different types of system for gaining of knowledge of the world. We therefore prefer to refer to two aspects of science: (1) its rough segmentation along the lines of "hard" and "soft", experimental and conceptual; and (2) the traditional relative independence of different scientific disciplines of both types. In fact, in much of the literature on the content of the term "science", the most that one can say of the many attempts to define its domains is that they are not very scientific. Designations like the natural sciences and humanities or social sciences, exact or hard and soft, allow a primitive classification, but do not show what such activities have in common or what the critical differences between them may be. To say that the scientific method is used in chemistry and anthropology adds little to the knowledge of how these sciences are carried out. Given the enormous variety of the targets or substrates of scientific effort, it appears to us more logical to define different domains of science according to the up-stream processes that occur and operate on the different substrates. We therefore refer to two domains of science, Science I and Science II, designated as Conceptual-Creative and Pragmatic-Invasive respectively.

In this picture, the creative cognitive processes of Science I, intuitive or reasoned, are in this picture essentially the same for all sciences, including mathematics and, as Lupasco suggested, also for art [33]. From a systems perspective they apply primarily to open systems, living and non-living, accessible and inaccessible. The processes of Science II apply to closed, prepared and primarily non-living systems to which changes can be made without ethical concerns, a chemical reactor, or more broadly computational science systems. Environmental science is clearly in the group of Science I, since the environment is not a closed system. Medicine is also, as the invasive changes it makes are in living beings, primarily human, involve ethical concerns and are far from being exact or independent of the critical patient-physician interaction. However, that they are limited in scope and the existence of some overlap between the two groups is not fatal to the discussion. In fact, as Hesse suggested in Hesse [34], continuum rather than dichotomy is the more appropriate model for the relation of the natural and human sciences.

\subsection{Science as Separation?}

In a standard account of the development of science, or scientific knowledge, two interacting processes occur: scientists start by making experimental observations and use these to generate laws 
and theories but also start with the latter to make predictions that are checked experimentally against them. In both cases, however, the target or object of the investigation will have been relatively narrowly defined. The derivation of the term from the Latin to cut or separate is well known. Objects and processes are separated from others to facilitate their analysis according to specific methodologies.

As a particular science becomes more complex, its development and understanding is facilitated by the use of knowledge and methods of other disciplines, which may be other sciences, mathematics, logic and so on. As a reviewer suggested, the German word Wissenschaft, which conveys the concept of the production of knowledge is in some ways more appropriate than science. We may call this contemporary stage that of multi-, inter- and transdisciplinarity of which one major acceptation is that of Nicolescu [35]. This process is being accelerated by the increasing computational power of the Informational and Communications Technologies (ICTs). A concomitant development is that of Systems Science, in which systems are described, not just as originally by von Bertalanffy as "complexes of elements standing in interaction" [36] but also ones from which physical parts cannot be removed without irreversibly damaging or destroying their ability to function.

\subsection{Methodology}

Although the concept of scientific method is too complex for further analysis here, there are other concepts of methodology, meaningful in the contemporary practice of science that we wish to keep at the center of our attention. The first group of these is, obviously, computational methods. They can be and are applied routinely in all the sciences. In addition, they have acquired associated disciplines such as the by now well-known computational philosophy of science [21], the philosophy of computation and other sub-disciplines. I suggest the work of Gordana Dodig Crnkovic as a primary reference in this area [37].

The second kind of method, which seems strictly limited to the human domain, is the application of an operative or organizational principle to an individual or social cognitive process to determine its dynamics, what "forces are at work". The target can be either the nominal subject of the science or the way in which the science can be structured. In the more formal logic of Lupasco [38], this would mean to seek, for each phenomenon, what phenomenon is primarily opposing it and to what extent the first is repressing or being repressed by the second. We will return to this methodology following the presentation below of this extension of logic to real phenomena made by Lupasco and developed further by Nicolescu and Brenner that is applicable to the discussion in this paper. For us, a critical word is "design"; the design of all scientific experiments, regardless of field, is a thought process that is itself a Science I.

The impact on science of the different properties and processes subsumed under the concept of information will depend on what kind of science is under discussion. As we will see, the non-standard, non-propositional logic proposed by Lupasco is for us is a key tool in understanding the dualistic nature of information, its philosophy and its science, and what we will show is a "revolution" in their currently evolving relation.

\section{Revolution in Philosophy}

\subsection{The Kuhnian Model}

The canonical model for this research on the revolutionary aspects of information is the now classical 1962 study by Thomas Kuhn: The Structure of Scientific Revolutions. It is immediately clear from subsequent work by Kuhn and others, both his followers and detractors, that there is no consensus either on what criteria define a revolution in science or whether the changes in progress in science and society constitute one or more revolutions. In this paper, well address two separate but obviously related questions: (1) is it correct to say that science and philosophy are converging in some manner and (2) is it important and useful to call attention to this development? Judging from the enormous amount of discussion of Kuhn's work that has taken and is still taking place, it would 
seem that whether or not a set of concepts constitute a revolution or not is a subject of great academic interest, if nothing else. Nickles has reviewed the literature on scientific revolutions in an authoritative article [39] from which we will take just one of the many questions asked: do all revolutions have the same structure and function, or are there diverse forms of rupture, discontinuity, or rapid change in science? Our answer is clearly yes.

This study has, however, identified an essential way in which a revolution in philosophy differs conceptually from a revolution in science: the latter refers to the dynamic form of changes in scientific theory; the former points to discontinuities in world-views. It should be clear that revolution does not automatically imply ethical progress but may only involve a change of authority. The National-Socialist (Nazi) seizure of power in 1933 that ended the democratic Weimar Republic was as much a revolution as the one that brought it into being by ending the Hapsburg monarchy in 1918. Regressions of this kind, albeit on a smaller scale, have been part of political history since at least the Peloponnesian Wars in Greece in the 5th century BCE. The further application of a term from political and social science to science in general has led to controversies which are by now familiar. The simplest and most informative way of deciding whether a development in knowledge or "thinking" has the character of a revolution is to define the latter as a major qualitative discontinuity, while recognizing that for any complex natural process, no discontinuity is absolute but always involves a degree of continuity.

Even in the case of science, we feel that there is a 4th logical and ontological dimension of incommensurability as a marker for revolution in addition to the epistemological dimensions identified by Kuhn. It is this logical dimension that is most relevant for a concept of revolutions in philosophy that it would now seem desirable to explore. The essence of standard notions of incommensurability is that scientific revolutions alter the very definition of science itself. They change the structural relations between pre-existing kind terms, breaking the non-overlap principle and resulting in a new ontology. The problem we have with this standard form of analysis is that it is essentially epistemological, without reference to real processes of knowledge acquisition which instantiate a dynamic ontology themselves.

We may thus ask first if an informational revolution in philosophy alters the very definition of philosophy itself. The answer is "yes". We can also ask if it results in a change in ontology. Our answer is "yes" but not in the "hard" incommensurable sense [40]: changes whether rapid or "revolutionary" cannot not embody, especially in the informational sense we discuss here, elements of prior knowledge and method. In our definition, all change is ontological.

\subsection{Current Concepts of a Revolution in Information}

As noted above, the concept of one or several revolutions in science has been accepted as a valid topic of research for some time. However, if one looks today at current volume of a major Western philosophical journal such as SYNTHESE, it is difficult to find references to any specific role of information, let alone a revolutionary one, even in articles dealing with foundational issues of ontology and quantum mechanics. The exception, of course, is the work of Luciano Floridi [41] and his identification of a "Fourth Revolution".

It thus has been a major objective of this article and of our joint work is to begin to redress this situation by documenting the way in which information can have a major impact on philosophy, on science and hence on the philosophy of science itself. As noted at the start of this paper, the concept of one or several revolutions in science has been accepted as a valid topic of research for some time. One notes of course the work of Thomas Kuhn and his commentators. The concept of a revolution in philosophy has also previously been formalized by Marx and in the 1950 by Ayer [42] and others, but it is certainly not the subject of extensive current debate. However, from the point of view of $\mathrm{Wu}$, a new "quiet" revolution in philosophy has been taking place in China since the early 1980s, with the recognition of the major impact on philosophy of the philosophy of information, considered as a metaphilosophy. This revolution is expressed in radical changes to the way fundamental philosophical problems can be conceived of and discussed. Wu has stated that in fact a revolution is 
occurring from the standpoint of the Philosophy of Information although the number of individuals involved, judged from a rough survey of publications, is probably still very limited.

The hermeneutic link that we establish is the following: information requires the re-introduction into science as well as philosophy of the neglected (because poorly grounded) dialectics of subject and object. To the extent that some non-Chinese thinkers embody and support a subject-object dialectics in their work, they participate ipso facto in the revolution in philosophy. The underlying humor in this situation is not a basis for not giving it the serious attention it deserves. The establishment and development of information science and technology occupy a unique and critical position in the 20th century science, constituting in the views of some workers a scientific and technological revolution. In 1999, Fang listed no less than six types of revolution in this field [43]. In the concept of Floridi [41], information is the 4th major revolution in the series communication (Gutenberg)—industrial一scientific. We are witnessing the establishment of an economy of knowledge and information and the emergence of a knowledge-based [44] information society.

This paper focuses on some of the theoretical aspects of the current revolution in philosophy, which we have identified. As Wu points out, the application of the Philosophy of Information involves a fundamental theoretical transformation operating the level of the highest paradigm of philosophy, that which discusses the structure of existence. It is this fundamental theoretical transformation that constitutes the revolution of philosophy. Its consequences can be expected to be further changes in all basic and non-basic problems and fields of philosophy.

\subsection{The Logic of Change and Revolution}

Change is ubiquitous in nature, and change in living systems, especially human thought and behavior is the most complex form of which we know. For human beings, two terms characterize change as rate, slow evolution and rapid revolution. The first applies to the biological or cognitive realm, the second only to cognitive disciplines and social structures. These processes can be further characterized by (1) their relation, that is, whether there is a continuous spectrum of change between them, or whether revolution implies a discontinuity; and (2) generality, the number of individuals involved and their degree of consciousness of being involved in drastic change. We claim that a change in the domain of philosophy has occurred and is occurring that, although neither instantaneous nor widespread, is sufficiently drastic to be called a revolution. Logic in Reality is a logic of change par excellence, and it would seem to provide both a framework and a language for the discussion of the revolutionary changes in philosophy.

\subsection{In Relation to Information Science}

As noted above, Wu has characterized his Philosophy of Information as a Metaphilosophy since it discusses ways in which all theories are constituted and operate in the evolving informational world. Following his outline for information, one may construct an "informational" model of knowledge that includes as its proper parts Information Science and its data. In the framework of Logic in Reality, the essential point is to recognize what brings together, rather than what differentiates or separates, the epistemological and ontological elements of information. In my LIR view, these are part of the content of Information Science.

There is an additional consequence of the proposed convergence occurring in thought. It is that if the philosophical implications of a scientific discovery are equally fundamental and revolutionary. In this case, it becomes more and more difficult to give priority to science as opposed to its philosophy, although they remain distinct. In the Copernican revolution, man was forced to see himself as being no longer at the center of a solar universe. Later, our importance was reduced further by the understanding that our solar system is a tiny spot at the edge of average galaxy, of which there are billions. Today, we must absorb and integrate into our thinking and being that the form of "ordinary" matter-energy of which we are composed is again only a small fraction of the total of which the universe is composed and evolves. A "logic of duality" enables one to be more comfortable about living with the ignorance 
that accompanies, dialectically, such increases in knowledge. They must be accompanied by increases in humility, or one becomes lost in Promethean technological fantasies.

\subsection{In Relation to Science in General}

Nothing in our discussion so far requires that any revolutionary movement be absolute, and one therefore must be able to distinguish degrees of revolutionarity. The criticism to be made here is that there will be two sets of observers whose positions must be taken into account: those who consider that a theory is moderately revolutionary, despite the absence of major discontinuity. Such a position cannot be distinguished from some forms of evolution. In fact, the absence of total separation between revolution and evolution is a second-order dialectical opposition to which the principles of LIR apply. Another process, to which attention is being paid in the field of biology, is devolution, a movement backwards toward prior states, and either more or less complex. Revolution and devolution thus constitute another duality in the same sense, often referred to today as evodevo (We note that evodevo has been taken by the editors of this Special Issue as a topic for discussion in the framework of a metaphilosophy of science).

It is important to note that there are other fields, such as biology, in which a convergence of science and philosophy has taken place without their necessarily being considered revolutionary. Neuroscience, on the other hand is being considered as undergoing a cognitive revolution. This consists in rejecting standard two-level views in favor of a fully integrated science of cognition. Boone and Piccinini [45], much in the spirit of this study, urge that the philosophical implications of this revolutionary shift in understanding be taken into account.

We now return to the theory of the philosophy of information as a metaphilosophy of $\mathrm{Wu}$ and on the impact of information on philosophy.

\section{The Metaphilosophy of Information}

\subsection{Philosophy and Metaphilosophy}

A standard definition of the term metaphilosophy, one that is apparently simple and non-controversial, is a statement or set of statements about philosophy. The Journal of Metaphilosophy lists the following definitions in its Aims and Scope: the foundation, scope, function and direction of philosophy, the following; the interrelations among schools or fields of philosophy; aspects of philosophical systems; the relation of philosophy to other disciplines and the justification (presumably by some form of truth-preservation) of philosophical methods and arguments. The concept that is lacking in this otherwise most desirable set of objectives, and also in the literature in general, is that of structure or functioning, in other words, the "how" rather than the "what" of philosophical argument.

We first note that a discussion of metaphilosophy requires a definition of both philosophy and the task of philosophy as well. In that of Sellars [46] "the aim of philosophy is to understand how things in the broadest possible sense of the term hang together in the broadest possible sense of the term". Sellars contrasted the understanding of the world that is possible for perceiving human beings, considered as free, rational agents, capable of self-perception ("manifest images") and the entities present in the macro- and micro-physical world that is understood through science ("scientific images"). His intent was ultimately the merging of these two conceptions, one self-referential and one not, in a synoptic vision or synthesis of "persons-in-the-world". Both Logic in Reality and Wu's Basic Theory of the Philosophy of Information provide a basis for understanding both the physical and epistemological dynamics of existence, that is, from where the properties of things come from that enable both them and the concepts of them to contrast, conflict and ultimately "hang together".

The recursive relation between philosophy and metaphilosophy instantiates this principle: (1) no aspect of one is totally devoid of aspects of the other, and any absolute division into first- and second-order problems is arbitrary; (2) the question of an infinite regress of "philosophies" does not arise. In the epistemology of LIR, iteration, in this case of real relations, stops after two or three stages 
because no new information is added by subsequent stages. The elements of knowledge and the knowledge of that knowledge are in a contradictorial relationship that exhausts the available mental configuration space. One can imagine an infinite regress as a process that does not stop, but in reality one stops it, or it stops itself [5], a reality noted by Aristotle himself.

A theory of metaphilosophy that talks only in terms of categorial separation or distinction between elements, disciplines or methodologies in philosophy is that of Toulmin [47]. In our view, any such theory has a certain limited domain of validity, in which it is more or less adequate or appropriate to the philosophy in question. The broader role of a Metaphilosophy of Information and by implication for all other disciplines has been given by Wu: "Now, my research is still basically limited to elucidate the general basic theory of philosophy of information from the angle of a metaphilosophy. At such a level, there is a lot of work we should do to define the philosophical essence of information, the philosophical shape and form of information; the nature of the different levels of information; a philosophical measure of information; the relationship between information and various prior definitions of its scope; information ontology, information epistemology, information methodology; the evolution of the informational world; information in material and social evolution; informational sociology and psychology; informational esthetics: an informational theory of value; there are still have very abundant and a large number of branch issues in the each area field of that listed above [48]." In our view, this conception of "meta-" does not conflict with that above of a recursive conceptual analysis. Philosophy and metaphilosophy are not totally disjunct in the process of philosophical ascent.

The article by Sebastian Sequoiah-Grayson, a collaborator of Floridi, entitled "The Metaphilosophy of Information [49] is one of the few on this subject. It supports Floridi's concept of strongly semantic information, but in fact indicates only two items of content of a "metaphilosophy of information": (1) that it should include "Shannon's Premonition" that there will always be a multiplicity of theories of information and (2) explications of the pre-theoretical notion of information are to be judged by their usefulness. These ideas are more or less acceptable in the context of this paper, but they do not say very much. We have found no other serious references to a Metaphilosophy of Information. Wu, through the substantial exposition and explicit references in [2] should be considered the pioneer in this field.

Our view thus offers a novel dialectic perspective on philosophy, metaphilosophy and their recursive relation. It naturalizes this relation, eliminating any implied circularity, since it does not require the total independence of premises and conclusion of standard logics. Starting from the fundamental properties of matter-energy, my theory permits a new approach to critical issues in both philosophy and science that is both logical and metaphilosophical. Wu's metaphilosophical view of information is not directed toward the codification of a Metaphilosophy of Information as yet another static discipline or body of knowledge. It is rather an attitude toward the position of an adequate Philosophy of Information as encompassing a critical component of all disciplines, beyond the scientific content specific to them. Metaphilosophy is not something "more abstract" than philosophy and it must be able to deal with the essential aspects of all disciplines and their theories.

\subsection{Informational Thinking and the Metaphilosophy of Information}

The Metaphilosophy of Information requires attention to the informational aspects of complex processes as a methodological necessity, in a process that $\mathrm{Wu}$ calls Informational Thinking. Informational Thinking (IT), as conceived of by $\mathrm{Wu}$, refers to a way of grasping and describing the essential characteristics and attributes of things by reference to the structure and dynamics of the information involved in their evolution, from their historical origins to future possibilities and probabilities. This strategy involves something like a Husserlian bracketing of the details of any complex process to consider the ways in which information functions in its dynamics, as well as the dialectical relations between its logical elements as proposed by LIR. However, the difference between Wu's theory and that of Husserl is obvious: the purpose of Wu's original Philosophy of Information is to clarify the nature of the dual existence and dual evolution of material and information 
in the objective world, starting from the logic of the existence and dynamics of the natural human self. The phenomenology of $\mathrm{Wu}$, unlike that of Husserl, does not have to be "naturalized", that is, brought into the domain of natural science. It is already there. The naturalization of Husserlian phenomenology was the subject of a major 1999 study [50]. Wu's approach eliminates the arduous task of finding natural equivalents for Husserl's transcendental intuitions. Wu then discloses directly the mechanisms of the processes involved in an individual's understanding at the level of the integrated object and subject, with internal and external interactions providing the necessary multi-level objective and subjective mediation.

\subsection{The Question of Phenomenology}

In this sense, all of the cognitive issues addressed by $\mathrm{Wu}$, especially informational values, valence and social evolution, have implied the use of Informational Thinking for their analysis. IT requires the abandonment of thinking in absolute material terms while retaining their commonsense foundations. IT is basically a methodological concept that, via the definitions of carriers and codes of information, enables inferences to be made about the historical and potential or probable future states of an information system. IT dialectically unifies energy factors and informational factors, determinism and indeterminism, internal and external feedback processes, independence (autonomy) and interdependence. LIR provides the additional logical structure for the dialectic interpretation of such a unified approach, based as we repeat on the impossibility of any total logical or physical separation between these dualities. In fact, Informational Thinking is the Metaphilosophy of Information in other terms. To the extent that Informational Thinking requires the consideration of all the philosophical and scientific facets of information, we believe that we are close to a new scientific (and logical) paradigm, a Unified Science of Information in which Informational Thinking, as opposed to thinking in terms of entities, results in new interpretations of, among other things, traditional disciplines and their theories. Above all, we see the (meta-) philosophy and (meta-) logic of information outlined here as a contribution to the naturalization of a process view of information as a whole. In other words, by seeing the relations between the changes in values that take place in human informational activities and the forms of society, a more profound understanding of information is possible that could be a contribution to overall progress and sustainable development of human civilization. Information Science, Metaphilosophy, Metalogic and Thinking may thus facilitate what Wu calls for, namely, a change in the commitment to and the interpretation of the dynamic oppositions in all complex natural processes in informational terms. Through the study of information as one of the most basic features of existence, and the formalization of informational activities, the Metaphilosophy of Information of Wu can and should change the way basic philosophical—metaphysical, epistemological and ontological—issues are discussed.

\section{The Impact of the Philosophy of Information on Philosophy}

\subsection{The Naïve Concept of the Opposition between Science and Philosophy}

The reality of the separation between science and philosophy refers to the opposing views of scientists and philosophers, in the absence of a satisfactory critique of science by philosophers and vice versa. As Wu discussed in detail in $\mathrm{Wu}$ and $\mathrm{Li}$ [51], it is an artifact of the conventional segmentation of existence in philosophy into matter-energy and mind. The Information Science and the Philosophy of Information have shown, as discussed in Section 4.2 above that there is (a) an in-itself world of information not identical to matter-energy and (b) the modality of mind is an informational activity constituted by for-itself and regenerated information. The mode of existence of the informational world is indirect, and information is a philosophical category indicating that indirect existence, which displays the state of the direct existing mode of the material world.

Based on this, we can say that the world is the co-existence of matter-energy and information (direct and indirect existence). However, then the basic question of philosophy must be changed to 
correspond with it to include the relationship not only between matter and mind but also matter and information and information and mind [7] (Wu often uses the term "spirit" in the Western sense of mind, pointing that the same word is used for both in Chinese).

\subsection{The Co-Evolution of Matter and Information}

A first consequence of the dual existence of matter and information is that both evolve in a synchronized way. "Things" (processes) being a composite of direct and indirect existence, they are both material and informational entities. This leads to an interior unification of time and space that complements the exterior unification of general relativity. In our theory, the information about the direct existence of past time is stored in patterns of space indirectly and the information about past time indicates changes in space, because the information about past time directly indicates the current structure or pattern of space.

This concept of the effective operation of the spatialization and the temporization of space as a logical interpretation of the Einstein theory was proposed by Lupasco in 1951 [38]. The interactions of "things" are, then, the processes of assimilation of the information in/of "things". The indirect existence of history constructs direct existence in its evolution and "passes it down" so to speak. This replacement of things by informationally functional processes is close to the recent naturalization of metaphysics by Ladyman and his associates in their provocatively entitled 2007 book Every Thing Must Go [52].

\subsection{Towards a New Theory of Knowledge, Man and Society}

We can only give some brief indications in this section of the major implications for philosophy of the above informational approach. We can now see that the maintenance of the relation between subject and object, but at the same time their recasting (See the work of Rafael Capurro [53] for further development of this important philosophical concept.) in informational terms makes possible an new understanding of the emergence of cognitive ability. The (human) subject's distinguishing of the object's information uses the subject's own characteristics to make clear the necessary relation of difference that defines cognitive content, which is knowledge.

The philosophical distinctions between nature and society, the essences of biology and psychology and so on can be eliminated in our new informational discourse. The origins and evolution of both humans and human society are cooperative processes of biologically inherited information patterns, psychological patterns of informational activity and informationally defined patterns of behavior. As Wu puts it, "A man is a multidimensional unification of natural and social existence, psychology, biology and behavior." The open-ended character of this multi-dimensional existence implies for human existence that, as postulated in Logic in Reality, it instantiates both determinism and indeterminism.

Finally, here, the understanding of the role of the informational world makes possible a new discussion of the value of information, and consequently of a new philosophy of value. The theory of the dual existence and dual evolution of matter-energy and information has the effect that their value is formed in their synchronous and diachronous interaction. As is discussed among other places in the field of Relational Quantum Mechanics [54], it is the interactions that are the primary existential mode, and "things" (see above), without their various interior and exterior interactions, do not exist. It is the universality of these interactions that confirm the fact and existence of value. Mental or cognitive value is the highest modality of informational value, but it is always, in the social field integrated with material value and in-itself information value. We believe our approach "naturalizes" a Durkheimian legitimation of metaphysics and the place of science in society, although we prefer a language of social processes to one of social facts. 


\subsection{Information Science, Again}

The existence of the subjects of a new field of existence-the informational world distinguished from the world of matter-energy which grounds it-within information science results in a new set of principles for scientific interpretations, especially one of holism rather than the reductionism prevalent in traditional philosophy. (This reductionism is unfortunately also present in many concepts of Information Science, which "stop" at the initial ones of Shannon derived from communications theory.) Our theory goes beyond their unity as expressed in the 1980s by Hofstadter [55] and also of their interaction, the fact that they do not totally conflict and contradict. Material entities and informational entities are always unified innately and concretely. Compared to the standard research principles of, say, systems science, self-organization, etc., the research principle of Information Science is more fundamental, more integrated and more representative of the complex processes of real existence. It refers to the modalities of systems, beyond their matter-energy, as types of relation, patterns, ways of organization and series of structures, and there relationships, patterns, ways of organization and series of structures can only be explained by the concept of information activity, where, again, matter-energy is only the carrier.

\section{The Informational Turn and the Convergence of Science and Philosophy}

\subsection{A Series of Turns. The Informational Turn}

We may summarize the view of the Philosophy of Information as a Metaphilosophy outlined in Section 6 above by stating that it provides a new bridge between science and philosophy which points toward their convergence. Information science and philosophy not only are not separated but also dynamically interact in the direction of a scientification of philosophy and a philosophization of science. The impact of the rapidly developing science of information on science, on philosophy and on the philosophy of science is thus an extremely complex recursive process, of which only a part has received detailed study. The changes in both the philosophy and science of information are reflected in what could be described from a philosophical standpoint as a foundational informational turn.

The evolution of philosophy starting in the last century can be summarized as a series of turns: the first is a linguistic turn, away from ontology toward epistemology. Its logic is standard linguistic logic. Next occur phenomenological and existential turns, whose logic is pure formal, linguistic logic. This is followed by the 1st ontological turn, due to the failure of descriptions of reality based on analytical, semantic criteria of truth toward what is. Its logic is paraconsistent, but still linguistic.

This 1st ontological turn implied a radical shift in science that should favor really scientific that is, non-absolute knowledge. However, the logical and philosophical tools were lacking for this purpose. The consequence has been the on-going narrowness and specialization of contemporary philosophy and an increasing separation of philosophy and science. As discussed by $\mathrm{Wu}$ [7], these so-called turns were not fundamental since they did not change the traditional ontological paradigm of classical Western philosophy, namely, the dualistic formula that existence $=$ matter + mind. Such a philosophy has "lost its capacity to explain and transform the world as a general view of it". Many aspects of the standard Philosophy of Science remain limited by their reliance on more or less classical concepts of models, semantics, and logic.

This has led to what we call a 2nd ontological turn, becoming the informational turn, taking on in the process its "revolutionary" character $[53,56]$. The logic of this turn is the Logic in Reality of Brenner indicated above.

\subsection{The Convergence}

As a consequence of the development of science, the universal, dualistic character of information has emerged clearly. In this view, in which science and philosophy are both present in a dialectical relationship, the world is constituted by matter-energy and information as its fundamental elements 
as discussed in Section 4. In the remainder of this section, we will discuss further implications of the informational turn for philosophy and the convergence of science and philosophy.

Evidence for the convergent trend we have identified, outside that of Information Science and Philosophy itself, comes from a number of different sources, both in China and the West. Examples are:

- $\quad$ Systems Science

- Intelligence Science

- Cybersemiotics

- Cognitive Semiotics

- Transdisciplinarity

- $\quad$ Angeletics (Messaging Theory)

- Information Ecology

- New (natural) Computational Theory

These disciplines share, in part, the cognitive dynamics of Information Science and the Philosophy of Information. The emphasis is on what unifies complex phenomena rather than on what appears to separate them, and on the joint applicability, at least in part, of conflicting theories. As Brenner has noted in Brenner [57], the intentionality of natural computation, presented in detail by Gordana Dodig Crnkovic [37], overlaps that of LIR as a description of reality.

\subsubsection{The Question of Computationalism vs. Natural Computation}

It is by now well established that computational approaches are at the center of developments in the theory and philosophy of information. It is clear that what form of computationalism is most adequate is a metaphilosophical issue. The theory comes in two major forms, (1) pan-computationalism or strong computationalism, which includes statements that the universe operates like a computer; and (2) a weaker form, developed by Gordana Dodig Crnkovic, informationalor info-computationalism which reflects Floridi's view of the universe as an informational structure, in which natural computation governs the dynamics of information.

Gordana Dodig Crnkovic has defined an Informational-Computational approach as follows: "Info-computationalism (ICON) relates to Floridi's program for the Philosophy of Information by contrasting it with a pan-computational stance, that of Zuse, Lloyd and others, which takes the universe to be a computer. With the universe represented as a network of computing processes at different scales or levels of granularity, ICON sees information as a result of (natural) computation. Adopting Floridi's Informational Structural Realism (see Section 9.3), which argues for the entire existing physical universe being an informational structure, natural computation can be seen as a process governing the dynamics of information.

It is thus necessary to distinguish carefully such approaches from that of a computational universe which assert that the universe is actually a digital, Turing-like computer that in fact computes using some digital code. While remaining agnostic about the question of fundamentality, Gordana Dodig Crnkovic replaces the emphasis where it belongs, namely on understanding that part of natural phenomena which may be subsumed under the concept of computation. It is to these ideas that the term natural computation, that is, information processing by natural systems, can be usefully applied. As Gordana Dodig Crnkovic points out, computationalism is not the world; it is a modeling framework that is acceptable within certain domains and does not exhaust our possibilities to relate to the world.

Within ICON, information and matter/energy are represented by information and computation. Computation presents implementation of physical laws on an informational structure. Instead of describing the world in terms of matter/energy (where energy stands for equivalent of matter) and information, as does $\mathrm{Wu}$, the info-computationalist approach makes the distinction between structure (information) and a process (computation). The mind/body problem is solved in a simple way. In this framework, there is no Cartesian divide between body and mind. Mind is a process, information 
processing, and body is a structure (proto-information). Thus, mind is a process of natural computation that results from dynamical reconfiguration/re-structuring of the information in the brain, in tune with the rest of the body, which connects it with the physical world.

Freed from the burden of the dogma of the computational universe, computationalism as natural computation appears as an acceptable component of a Metaphilosophy of Information. It grasps (a term often used by $\mathrm{Wu}$ many features of natural processes. This naturalized epistemology approach, conceptualizes information as both here (intelligence), there (world) and on the interface, as information constitutes the basic "stuff" of existence. Its structural changes are the results of computational processes. Within this framework of dual-aspect informationalism/computationalism (info-computationalism), matter may be viewed as a structure (information), in a permanent process of flow-natural computation. This subject has been discussed in detail by Gordana Dodig Crnkovic in a recent compendium [58].

This work thus presents a synthesis of two paradigms within contemporary philosophy-computationalism and informationalism into a new dual-aspect info-computationalist framework. The dualism itself does not mean that the phenomena are separated, and exclude each other. On the contrary, they are mutually determining, constraining and completely indissoluble. The structures and the processes are inseparably interwoven by physical laws, and LIR gives logical underpinning to the dynamics of "interwoven".

The key further moments of Wu's latest views of the origin and characteristics of convergence of science and philosophy are as follows.

\subsubsection{Rationality}

If science reflects the rational thinking of human beings, the thinking that corresponds to the reception of sensorial evidence, from experiment, cannot be separated from a more universal form of rational thought, which $\mathrm{Wu}$ calls rationality or universal rationality. Science incorporates or involves, from the beginning, concepts that are primarily philosophical or we might say metascientific - a worldview, an epistemology, a methodology but it ends in universal rationality. For a more standard but still useful view of rationality we refer to the 2001 book of the philosopher J. D. Searle, Rationality in Action [59] in which a distinction, but not an absolute classical separation between internal and external reasons for action is established.

We thus see, for the description of the cognitive evolution of phenomena, that its science and philosophy are reciprocally related, as conjugate variables, with sensitivity maximized in science and rationality maximized in philosophy. Another way of expressing this idea is by using the Lupasco logic: one can say, for phenomena at the lowest physical level that their science is actualized and their philosophy is potentialized and for highest level phenomena that their philosophy is actualized and their science is potentialized (that is, not absent or eliminated but not focused on). This reciprocity applies also to the views of science by philosophy and vice versa: each considers the other field more limited, and this should be an indication that both are true and not true at the same time, which is a logical statement within Logic in Reality. Both science and philosophy instantiate their inherent relations of unity and complexity.

The norm for us is that the universal scientific rationality is saturated with philosophical concepts. The unity of philosophy and science cannot be seen as just an external convergence, but as an inherent amalgamation in which, however, the disciplines do not totally lose their identity and specificity.

Despite the criticism by some authors of the concept of cognitive levels, in the case of both universal rationality and science, we consider that it applies naturally. It is not that the highest level is philosophy and the lowest science, but there is no philosophy that is not partly science and no philosophy that is not partly science. We may state the same thing for the science and philosophy that Brenner stated for science and logic: at the beginning they were integrated; then were separated and today, under the influence of information in the broadest sense, they can be viewed as undergoing 
a metaphilosophical (or metascientific) rejunction. It should be obvious that this process does not take place equally or at the same rate for all the sciences, but we are looking here at a general trend.

The strongest force for change in philosophy (or human thought in general) is thus science, in particular information science, and this state of affairs must influence the foundations of the Philosophy of Science per se. This does not mean that philosophy has only a passive role in this process. On the contrary, if there are no philosophical initiatives, the Philosophy of Science could not evolve on its own. We thus need to add to the basic concept of the non-separability of philosophy and science the further layer of critique of the Philosophy of Science. Note also the comment above regarding the relevance of the German term Wissenschaft-knowledge-production-to the discussion. We point towards such a new critique in our concluding Section 11.2.

\subsection{The Self-Critique of Philosophy and the Philosophy of Information: Wu and Floridi}

In the view of $\mathrm{Wu}$, the natural self-transformation of philosophy is achieved by the transition between levels of scientific rationality, with the assimilation of new, external information. This, however, must accept the regulation of philosophy itself, that is, to be exposed to choice and critique. There is a double effect in this process of assimilation: on the one hand, external information is criticized by philosophy; on the other hand, because that critique changes the original structure of philosophy, this ipso facto constitutes as critique of philosophy.

It is the contemporary Philosophy of Information, especially in Wu's acceptation of it, which shows the development of philosophy through this form of dual criticism. It enables the debate about information to proceed on a new basis, avoiding the analogies used to match information with conceptions of the outmoded paradigm of traditional philosophy (information is a property of matter; information is meaning; information is a mental entity, etc.).

In summary, this Philosophy of Information that shows the general character of information transcends the basic beliefs and theories of traditional philosophy. The new PI is based on the concept that philosophy impacts science at the same time that philosophy acts on itself. We conclude that the birth of the modern Philosophy of Information leads to the first fundamental turn of philosophy itself.

We are now in a position to analyze the similarities and differences between the approaches of $\mathrm{Wu}$ and Floridi to the Philosophy of Information. It is clear that these are different, partially complementary views in which all the major issues of the foundations of information are addressed. Brenner has outlined these views in the readily accessible [57], and we provide a summary here. As we have seen in this paper, the work of Wu is better described as a Metaphilosophy of Information, since it includes a vision of the operation of the Philosophy of Information as drastically changing the content of philosophy itself.

In 2004, Floridi listed some eighteen open problems in the philosophy of information [60]. One of the most important was whether meaning can at least partly be grounded in an objective, mind-, and language-independent notion of information (naturalization of intentionality). Is it possible to analyze both information and meaning not truth-functionally but as having the potential or being a mechanism to change the informational context? (Our answer is of course yes.)

Floridi provided a detailed theory (action-based semantics) of how data acquire meaning as the indispensable foundational picture of semantic information and information processing upon which the informational aspects of theories of meaning and of society can be soundly based. The question that Floridi did not ask, however, is whether some form of ontological commitment is necessary for a complete theory of information. We obviously think that one is and that this is a crucial aspect of the Philosophy of Information of Wu.

Floridi does argue, for example, in his Philosophy of Information [1] that digital ontology, according to which the ultimate nature of reality is digital or computational, should be carefully distinguished from informational ontology, according to which the ultimate nature of reality is structural. Floridi avoids the Boolean digital vs. analogue dichotomy in favor of an Informational Structural Realism (ISR), according to which knowledge of the world is knowledge of its structures. 
The most reasonable ontological commitment favors an interpretation of reality as the totality of its structures, energetic entities, dynamically interacting with one another. His Informational Structural Realism (ISR) thus appears to provide an ontology applicable to both sub-observable and to observable structural objects by translating them into informational objects, defined as cohering clusters of data, not in the alphanumeric sense of the word, but in an equally common sense of differences de re, i.e., mind-independent, concrete points of lack of uniformity.

These cohering clusters of data as relational entities are the elementary relata required in Floridi's ISR. The structuralism in question here is based on relational entities (understood structurally) that are particular, not on patterns that are abstract and universal (We recall the key feature of non-separability of the LIR ontology. LIR simply extends it as an accurate general ontological picture of the dynamic processes of change. A complex process and its opposite or contradiction "come together" or do not exist).

Floridi's position is that the ultimate nature of reality is informational, and it makes sense to adopt a view of reality as mind-independent and constituted by structural objects that are neither substantial nor material (they might well be, but we have no need to suppose them to be so) but informational. Logic in Reality, however, offers a principled basis for saying that they are and suggests the logical rules they follow. As Brenner has also shown [61], the Floridi ontology fails to capture the evolution of real informational processes. The critical aspect of information, to which Hofkirchner and others are now turning, is its dualistic relation to the energy of which it is constituted. In our view, it is this duality or dualism that is the actual "driver" of informational processes.

\section{Unity; Towards a Unified Science of Information}

\subsection{The Question of Unity}

As one philosophical consequence of our theory of the omnipresence of information in science and knowledge, we ask ourselves if it is relevant to the question of the Unity of Science. We note first that when almost any subject is presented as a unity, it is always with a positive valence. A unity is something desirable and desired in whatever forms the unity presents itself: a unified theory, a search for invariants and so on. In a perhaps too rapid analysis, Lupasco associated our search for invariants, e.g., in 20th century physics and other unities as a psychological expression of the logical antagonism of ourselves as living beings, that is, instantiations of diversity, growth and death.

Without going more deeply into this question, if one looks at the authoritative article by Cat in the Stanford Encyclopedia of Philosophy [62], one is struck by the diversity of senses that can be given to the definition of unity! These range from the possible single nature of the underlying "stuff" of the universe, to the unification of the disciplines within science and with regard to these whether on is dealing with concepts or terms or the higher-level entity of theory and whether the relations are ones of reduction, explanation or logical inference.

Cat suggests that the concept of unity can have value at the practical level in science, to justify approaches and goals, and in philosophy to help choose what philosophical questions to pursue and what target areas to explore. The Unity of Science could suggest what science is to be referenced by philosophy as authoritative. He touches upon our point in the first paragraph by suggesting "unities and unifications help us meet cognitive and practical demands upon our life ..., contribute to our self-image and be seen as a source of aesthetic value, providing a grip on our intellectual imagination".

Our approach extends this view: this picture of the value of the Unity of Science, self-referentially, is itself a unity of a sort that neglects, intentionally or not, the value of diversity, or, as we believe is equivalent, believes that it is necessary to do so explicitly. Informational processes however, as we have seen throughout this paper, are a composite of unities and diversities, in the complex dynamic structures of the LIR perspective. Our dualism has been well captured by Marcin Schroeder in his contribution to the concept of natural computation [63]. "The naturalistic perspective on computing is based on the observation that every computation is inherently analogue, and the distinction between 
analogue and digital is only a matter of its meaning". In the LIR picture of the evolution of real processes, of course, the (logical) elements involved are all "analogue".

Let us discuss two of the components of our proposed Unified Science of Information.

\subsection{A General or Unified Theory of Information}

The objective of finding a unifying information theory that would synthesize all existing approaches in an amalgamated structure of ideas, constructions, methods and applications has been perhaps best approached by Mark Burgin in his General Information Theory [64]. We first note that a General Theory of Information (GTI) is not a Unified Science or Theory of Information. The former involves only practical information science at the basic theoretical level, while the latter is part of a broader informational paradigm, as we will see.

In his book, Burgin integrated perspectives on information from logic, epistemology and systems theory in a rigorous, parametric mathematical framework. In the case of the GTI, the parameter is very general. This parametric approach provides a tool for building the GTI as a synthesis, which organizes and encompasses all main directions in information theory. Abstract categories allow one to develop flexible models for information and its flow, as well as for computers, networks and computation. Another type of model establishes functional representation of infological systems representing information as an operator in functional spaces.

Burgin considers his GTI has provided solutions to various problems via the unifying concept of an infological system, concepts of different types of information and types of different concepts of information. At the highest cognitive level, the qualitative dimension of information, in particular, meaning and its evolution are clearly listed by Burgin among the critical areas for further work, "to form a unified system of information quality characteristics and measures and study their properties in the context of a GTI". Although Burgin favors mathematical modeling of intelligence, mind and instinct also in the context of a GTI, he nowhere excludes non-mathematical approaches.

From our perspective, there are cognitive and other informational processes which are non-computable, that is, algorithms cannot be written for them. Although the mathematical approach has and will retain an essential relation to these also, any explanation of these must therefore ultimately be based on principles that go beyond those parts of those processes that can be modeled mathematically.

In a recent article, Brenner has summarized a number of other currently debated theories of information of interest by Luhn, Markov and Marijuan but none of these are as exhaustive as that of Burgin and they will not be discussed further here. We now turn to the next level, that of a Unified Theory of Information.

We note first that the scheme of principled distinctions proposed by $\mathrm{Wu}$ has a relationship to and a place in the conceptual approaches that Hofkirchner has recently listed for a Unified Theory of Information (UTI). Hofkirchner [23] among others has argued for the desirability of a UTI that would encompass the different manifestations of information processes. Such a UTI should be capable of balancing the apparently contradictory properties of information-physical and non-physical, universal and particular-without reduction. Its underlying principle should be "as abstract as necessary but as concrete as possible at the same time".

Hofkirchner considers information as a "superconcept", which includes a group of overlapping concepts such as message, signal, etc. as they apply to communication, cognition and cooperation between human and non-human organisms. Hofkirchner asks how matter and idea, mind, information, etc. can be grasped as complements and with them information as a thing (a structure, a flow) or as a human construction. Hofkirchner gives a dialectical answer to the implied division between subject and object, suggesting that mind, and with it information, is of a different "materiality" than "non-emergent" states of matter. His own approach to a Unified Theory of Information (UTI) is to eliminate the absolute and in my view artificial separation between critical concepts of information in favor of a dialectical relationship similar to the ancient intuition of "unity-in-diversity". Specifically, 
his "UTI seeks a concrete-universal concept of information rather than an abstract one". Hofkirchner wishes to avoid reliance on a "formal-logical figure of necessary and sufficient conditions" and use a way of thinking that integrates as well as differentiates the particular and universal", with is consistent with Logic in Reality.

\subsection{Toward a Unified Science-Philosophy of Information}

In contrast to the above designations, a Unified Science of Information (USI) would include them, as major levels, together with a Philosophy of Information, a General Theory of Information and various forms of Informatics covering the technological aspects of information. However, a USI would not be limited to these fields. It would be both the effect of the convergence of science and philosophy, including those of information, and the cause of further integration of science and philosophy in which the philosophical sense of the science of information and the scientific character of the philosophy of information would be completely present in a new integrated pattern of human knowledge.

As a result of its continuity across all levels of human knowledge from philosophy to science to technology, a USI would be a disciplinary system that can be described in Chinese by the metaphor of "standing upright between heaven and earth". This metaphor captures the role of information in providing a link between phenomena at the lowest physical level and at the highest human cognitive level.

The further development of a Unified Science of Information (USI) should lead, in this view, to further integration of science and philosophy in which the philosophical character of Information Science and the scientific character of the Philosophy of Information (PI) become readily apparent. The Philosophy of Information (PI) could be viewed as a part of a USI, and the USI would achieve its real ground as a general provision of philosophy as a whole. In other words, the USI is the scientific basis of the PI, and the PI is the general philosophical precondition of a USI. The convergence of the two represents an integrated pattern of development of contemporary human knowledge.

As we have seen, there is a set of new and unique relationships that are developing between the classical disciplines of science and philosophy as a consequence of new understandings of the science and philosophy of information. The overall movement is that of a philosophization of science and a scientification of philosophy leading to their convergence. However, in this paper and elsewhere, we have used the term Unified Science of Information. This is not strictly accurate, as our convergent theory includes the Philosophy of Information as a proper part, without conflation. We therefore propose, despite its awkwardness, the term Unified Science-Philosophy of Information (USPI) as the best possible description of our field of endeavor.

The philosophical stance of USPI may be usefully compared to Hofkirchner's proposal [65] of a Praxio-Onto-Epistemology (POE) as "a response to the current developmental requirements of humanity". While traditional approaches are apparently stuck in the three disciplines as alternatives, POE offers a transdisciplinary response for going beyond them, resembling LIR in this respect.

\subsection{Towards an Informational Metaphilosophy of Science}

We can conclude from the above that a proper new philosophy of science is an informational metaphilosophy, in that (the science of) information defines both new content of the philosophy of science and new dynamics of the relations between a science and its philosophy. A question of interest to readers will be that of the consequences of this convergence for the Philosophy of Science itself. In the spirit of this paper, we suggest that as the special sciences become more and more informational, their respective philosophies can be included as part of the philosophical aspects of the Unified Science-Philosophy of Information (UPSI). At the same time, logically, the informational-philosophic aspects of the USPI can become part of the general Philosophy of Science. All of these considerations, however, are clearly metaphilosophical, since they touch on the content of the respective philosophies (of information and science). We therefore tentatively conclude that the dynamics of the processes can be captured in the concept of a trend toward an Informational Metaphilosophy of Science as the most 
appropriate model of knowledge. This Philosophy-Science justifies a new non-reductionist view of the world in which it is ethically impossible to maintain any scientific basis for economic, social or ethical exclusion. The use of this doctrine to promote the development of an information commons and the common good is thus a moral as well as a methodological imperative. We consider this, therefore, a necessary area for further research.

\section{Conclusions. A Revolutionary Attitude}

\subsection{Summary}

In this paper, we have first presented the concept of a process by which the properties of information, collated in Information Science and Philosophy, enable it to function as an operator [66] to change the nature of science and philosophy themselves, with a functional role in the emerging information society, including how science and philosophy are done. We see the Informational Stance of the practitioners of Informational Science as a guarantee of avoiding limited, reductionist positions and applications of our informational approach in the areas of perception and cognitive science, consciousness and the understanding of personal identity. As this approach affects disciplines, in view of the prestige that information has even at the lowest intellectual levels, it may become a basis for application to the social and political structures of society.

We have shown, in our discussion, the central role of Logic in Reality (LIR) a non-standard, non-propositional logic that can handle the contradictions and inconsistencies of the real, informational world. LIR provides a logical framework for the most important interactive relations discovered by $\mathrm{Wu}$ in the relation between the informational world and the world of matter-energy on which it is based. Although we do not deny that in principle another such non-propositional logic system might accomplish the same task, neither we nor anyone who has ever commented on our logic has ever been able to identify one.

\subsection{The Question of "Turn' vs. "Revolution". The Revolutionary Attitude}

We conclude that the current informational revolution defines a discontinuity in thought that justifies calling it a revolution in philosophy itself, but we specify that it be as a change in attitude that the revolution could become concretized. Wu has defined the Informational Attitude or Stance (IS) as a philosophical position most appropriate for, and not separated nor isolated from, the emerging science and philosophy of information itself. IS requires attention to the informational aspects of complex processes as a methodological necessity.

Application of an Informational Stance would involve defining, for each concept in information research, in all of science and in fact of all knowledge not only its scientific and philosophical aspects but also their interaction and co-modification. The major consideration of such a stance associated with a Unified Science-Philosophy of Information is thus that of giving proper value to its qualitative, non-measurable and non-computable components. It should never be said that qualitative relations and inequalities that follow the rules of Logic in Reality are more important or necessary than the quantitative equalities, only that they are no less fundamental.

We consider that a Revolutionary Attitude is now a necessary part of the intellectual world, embodying several functions. It would be revolutionary for people to change the dynamics of their acceptance of the published literature, exercising the principle of tolerance but also rigor that Nicolescu has insisted are the main attributes of the Transdisciplinary Attitude. Other multi- and interdisciplinary movements, such as that of Translational Medicine, emphasize the need for a radical break with accepted ways of realizing the medical benefits to the patient of fundamental research in biology. The consequences of such a Revolutionary Attitude remain to be defined, but they hopefully would accompany a corresponding positive change in the economic and social structure of society as a whole.

Author Contributions: Both authors contributed to this paper. 
Conflicts of Interest: The authors declare no conflict of interest.

\section{References}

1. Floridi, L. The Philosophy of Information; Oxford University Press: Oxford, UK, 2010.

2. $\mathrm{Wu}, \mathrm{K}$. The Basic Theory of the Philosophy of Information. In Proceedings of the 4th International Conference on the Foundations of Information Science, Beijing, China, 21-24 August 2010.

3. $\mathrm{Wu}, \mathrm{K}$. The Interaction and Convergence of the Science and Philosophy of Information. Philosophies 2016, 1, 228. [CrossRef]

4. Hooker, C.A. Philosophy and Meta-Philosophy of Science: Empiricism, Popperianism and Realism. Synthese 1975, 32, 177-231. [CrossRef]

5. Brenner, J. Logic in Reality; Springer: Dordrecht, The Netherlands, 2008.

6. Kuhlmann, M.; Pietsch, W. What Is and Why Do We Need Philosophy of Physics? J. Gen. Philos. Sci. 2013, 43, 209-214. [CrossRef]

7. Wu, K. The Development of Philosophy and Its Fundamental Informational Turn. Information 2015, 6, 693-703. [CrossRef]

8. Kolin, K.K. The Globalization of Social Information and Humanistic Revolution. In Proceedings of the Chinese-Russian Conference on Information Science, Wuhan, China, 20 September 2013.

9. Li, Z. The Worldview and Methodology of Information Science. In Proceedings of the International Conference on Philosophy of Information, Xi'an, China, 18-21 October 2013.

10. Ursul, A. On the Nature of Information. Probl. Philos. 1965, 3. (In Russian) [CrossRef]

11. Yan, X. Information Science: Concept, System and Perspective; Beijing Press: Beijing, China, 2016. (In Chinese)

12. Wu, K. The Partition of the Existent Field and the "Whole New" Sense of the Philosophy of Information. Humanities. J. 2013, 5, 1-6. (In Chinese)

13. Wu, K.; Brenner, J. Informational Thinking and Systems Thinking: A Comparison. In Proceedings of the Foundations of Information Conference, Moscow, Russia, 13 June 2013.

14. Schroeder, M.J. Foundations for Science of Information: Reflection on the Method of Inquiry. Triple-C 2011, 9, 377-384.

15. $\mathrm{Wu}, \mathrm{K}$. The Informational Scientification of Science. Qinghai Soc. Sci. 1997, 2, 53-59. (In Chinese)

16. Brenner, J. Wu Kun and the Metaphilosophy of Information. Int. J. Inf. Theor. Appl. 2011, 18, 103-128.

17. Wu, K.; Brenner, J. The Informational Stance: Philosophy and Logic. Part I: The Basic Theories. Log. Log. Philos. 2013, 22, 453-493.

18. Brenner, J. Information in Reality: Logic and Metaphysics. Triple-C 2011, 9, 332-341.

19. Deacon, T.W. Incomplete Nature. How Mind Evolved from Matter; W.W. Norton \& Co: New York, NY, USA, 2011.

20. Wu, K. The Essence, Classification and Quality of the Different Grades of Information. Information 2012, 3, 403-419. [CrossRef]

21. Thagard, P. Computational Philosophy of Science; The MIT Press: Cambridge, MA, USA, 1993.

22. Brenner, J. A Logic of Ethical Information. Knowl. Technol. Policy 2010, 23, 109-133. [CrossRef]

23. Hofkirchner, W. How to achieve a unified theory of Information. Triple-C 2009, 7, 357-358.

24. McGinn, C. Basic Structures of Reality. Essays in Meta-Physics; Oxford University Press: Oxford, UK, 2011; p. 160.

25. Wu, K.; Brenner, J. An informational ontology and epistemology of cognition. Found. Sci. 2014, 20, $249-279$. [CrossRef]

26. Symons, J. Applying Logic; Some remarks on the reciprocal influence of experimental and formal investigations of identification. In Open Problems in Epistemology; Hintikka, J., Ed.; Philosophical Society of Finland: Helsinki, Finland; Available online: http:/ /www.johnsymons.net/wp-content/uploads/2012/04/ Apply-Logic.pdf (accessed on 8 August 2017).

27. Derrida, J. Of Grammatology; Johns Hopkins University Press: Baltimore, MD, USA; London, UK, 1974.

28. Priest, G. Paraconsistent Logic. In Handbook of Philosophical Logic; Gabbay, D., Guenthner, F., Eds.; Kluwer Academic: Dordrecht, The Netherlands, 2000.

29. Gare, A. Introduction: The Future of Philosophy. Cosm. Hist. J. Nat. Soc. Philos. 2012, 8, 1-17.

30. Cifone, M. Nothingness and Science (A Propadeutic). Cosm. Hist. J. Nat. Soc. Philos. 2014, 10, $251-274$. 
31. Wheeler, J. At Home in the Universe; American Institute of Physics Press: Woodbury, NY, USA, 1994.

32. Brenner, J. Stéphane Lupasco et la Rejonction Métalogique. In À la confluence de deux cultures. Lupasco aujourd'hui. Actes du colloque international UNESCO; Éditions Oxus: Paris, France, 2010; pp. 251-286.

33. Lupasco, S. Logique et Contradiction; Presses Universitaires de France: Paris, France, 1947.

34. Hesse, M. Revolutions and Reconstructions in the Philosophy of Science; Indiana University Press: London, UK, 1980.

35. Nicolescu, B. Manifesto of Transdisciplinarity; State University of New York Press: Albany, NY, USA, 2002.

36. Von Bertalanffy, L. General System Theory; George Braziller: New York, NY, USA, 1969.

37. Dodig Crnkovic, G. Nature as a network of morphological infocomputational processes for cognitive agents. Eur. Phys. J. Special Topics. 2017, 226, 181-195. [CrossRef]

38. Lupasco, S. Le Principe D'antagonisme et la Logique de L'énergie; Éditions du Rocher: Paris, France, 1987; Originally published in Paris: Éditions Hermann, 1951.

39. Nickles, T. Scientific Revolutions. In The Stanford Encyclopedia of Philosophy (Winter 2016 Edition); Zalta, E.N., Ed.; Stanford University: Stanford, CA, USA, 2014; Available online: http: / plato.stanford.edu/archives / win2016/entries/scientific-revolutions/ (accessed on 17 March 2017).

40. Oberheim, E.; Hoyningen-Huene, P. The Incommensurability of Scientific Theories. In The Stanford Encyclopedia of Philosophy (Winter 2016 Edition); Zalta, E.N., Ed.; Stanford University: Stanford, CA, USA, 2014; Available online: http://plato.stanford.edu/archives/win2016/entries/incomensurability / (accessed on 7 January 2016).

41. Floridi, L. The Fourth Revolution. How the Infosphere is Reshaping Human Reality; Oxford University Press: Oxford, UK, 2014.

42. Ayer, A.; Kneale, W.; Paul, G.; Pears, D.; Strawson, P.; Warnock, G.; Wollheim, R. The Revolution in Philosophy; Macmillan: London, UK, 1950.

43. Fang, I. A History of Mass Communication. Six Information Revolutions; Focal Press: Waltham, MA, USA, 1997.

44. Leydesdorff, L. The Knowledge-Based Economy; Universal Publishers: Boca Raton, FL, USA, 2006.

45. Boone, W.; Piccinini, G. The Cognitive Neuroscience Revolution. Synthese 2016, 193, 1509-1534. [CrossRef]

46. De Vries, W. Wilfrid Sellars. In The Stanford Encyclopedia of Philosophy (Winter 2016 Edition); Zalta, E.N., Ed.; Stanford University: Stanford, CA, USA, 2014; Available online: http:/ / plato.stanford.edu/archives / win2016/sellars/ (accessed on 8 August 2017).

47. Toulmin, S. Knowing and Acting. An Invitation to Philosophy; Macmillan: New York, NY, USA; London, UK, 1976.

48. Wu, K. Philosophy of Information-A New Spirit of the Time; Shaanxi Normal University Press: Xi'an, China, 1989. (In Chinese)

49. Sequoiah-Grayson, S. The Metaphilosophy of Information. Minds Mach. 2007, 17, 331-334. [CrossRef]

50. Petitot, J.; Varela, F.; Pachoud, B.; Roy, J.-M. (Eds.) Naturalizing Phenomenology Issues in Contemporary Phenomenology and Cognitive Science; Stanford University Press: Stanford, CA, USA, 1999.

51. Wu, K.; Li, P. Scientific Evolution: The transformation of the scientific worldview and way of thinking. J. Chin. Renmin Univ. 2008, 3, 41-46. (In Chinese)

52. Ladyman, J.; Ross, D. Every Thing Must Go. Metaphysics Naturalized; Oxford University Press: Oxford, UK, 2007.

53. Brenner, J. The 'Naturalization' of the Philosophy of Rafael Capurro. In A Festschrift in Honor of Rafael Capurro; Kelly, M., Bielby, J., Eds.; Springer Fachmedien: Wiesbaden, Germany, 2016; pp. 45-64.

54. Laudisa, F.; Rovelli, C. Relational Quantum Mechanics. In The Stanford Encyclopedia of Philosophy (Spring 2002 Edition); Zalta, E.N., Ed.; Stanford University: Stanford, CA, USA, 2002; Available online: http:/ / plato.stanford.edu/archives/spr2002/entries/qm-relational/ (accessed on 13 November 2007).

55. Hofstadter, D.; Dennett, D. The Mind's I; Basic Books: New York, NY, USA, 1981.

56. $\mathrm{Wu}, \mathrm{K}$. The Interaction and Convergence of the Philosophy and Science of Information. In Proceedings of the 2nd International Conference on the Philosophy of Information, Vienna, Austria, 6 June 2015.

57. Brenner, J. Information: A Personal Synthesis. Information 2014, 5, 134-170. [CrossRef]

58. Dodig Crnkovic, G.; Giovagnioli, R. (Eds.) Computing Nature. Turing Centenary Perspective; Springer: Berlin, Germany, 2013.

59. Searle, J. Rationality in Action; MIT Press: Cambridge, MA, USA, 2001.

60. Floridi, L. Open Problems in the Philosophy of Information. Metaphilosophy 2004, 35, 554-582. [CrossRef] 
61. Brenner, J. Levels of Abstraction; Levels of Reality. In Luciano Floridi's Philosophy of Technology; Demir, H., Ed.; Springer: Dordrecht, The Netherlands, 2012.

62. Cat, J. The Unity of Science. In The Stanford Encyclopedia of Philosophy (Winter 2014 Edition); Zalta, E.N., Ed.; Stanford University: Stanford, CA, USA; Available online: http:/ / plato.stanford.edu/archives/win2014/ entries/scientific-unity/ (accessed on 28 February 2017).

63. Schroeder, M. Dualism of Selective and Structural Manifestations of Information in Modelling of Information Dynamics. In Computing Nature. Turing Centenary Perspective; Dodig Crnkovic, G., Giovagnioli, R., Eds.; Springer: Berlin, Germany, 2013; pp. 125-137.

64. Burgin, M. Theory of Information. Fundamentality, Diversity and Unification; World Scientific: Singapore, 2010.

65. Hofkirchner, W. Emergent Information. A Unified Theory of Information Framework; World Scientific: Singapore, 2013.

66. Burgin, M.; Brenner, J. Operators in Nature, Science, Technology and Society: Mathematics, Logic and Philosophy. Philosophies 2017, 2, 21. Available online: http://www.mdpi.com/2409-9287/2/3/21 (accessed on 17 September 2017). [CrossRef]

2017 by the authors. Licensee MDPI, Basel, Switzerland. This article is an open access article distributed under the terms and conditions of the Creative Commons Attribution (CC BY) license (http:/ / creativecommons.org/licenses/by/4.0/). 